\title{
Physical Exercise and Antidepressants Enhance BDNF Targeting in Hippocampal CA3 Dendrites: Further Evidence of a Spatial Code for BDNF Splice Variants
}

\author{
Gabriele Baj ${ }^{1,4}$, Valentina D’Alessandro',4, Laura Musazzi ${ }^{2}$, Alessandra Mallei ${ }^{2}$, Cesar R Sartori ${ }^{3}$, \\ Marina Sciancalepore', Daniela Tardito ${ }^{2}$, Francesco Langone ${ }^{3,5}$, Maurizio Popoli ${ }^{2}$ and Enrico Tongiorgi*, \\ 'Department of Life Sciences, BRAIN Centre for Neuroscience, University of Trieste, Trieste, Italy; ${ }^{2}$ Center of Neuropharmacology - Department \\ of Pharmacological Sciences and Center of Excellence on Neurodegenerative Diseases, University of Milano, Milano, Italy; ${ }^{3}$ Department of \\ Physiology and Biophysics, Institute of Biology, State University of Campinas, UNICAMP, Campinas, Brazil
}

Brain-derived neurotrophic factor (BDNF) is encoded by multiple BDNF transcripts, whose function is unclear. We recently showed that a subset of BDNF transcripts can traffic into distal dendrites in response to electrical activity, while others are segregated into the somatoproximal domains. Physical exercise and antidepressant treatments exert their beneficial effects through upregulation of BDNF, which is required to support survival and differentiation of newborn dentate gyrus (DG) neurons. While these DG processes are required for the antidepressant effect, a role for CAI in antidepressant action has been excluded, and the effect on CA3 neurons remains unclear. Here, we show for the first time that physical exercise and antidepressants induce local increase of BDNF in CA3. Voluntary physical exercise for 28 consecutive days, or 2 -week treatment with $10 \mathrm{mg} / \mathrm{kg}$ per day fluoxetine or reboxetine, produced a global increase of BDNF mRNA and protein in the neuronal somata of the whole hippocampus and a specific increase of BDNF in dendrites of CA3 neurons. This increase was accounted for by BDNF exon 6 variant. In cultured hippocampal neurons, application of serotonin or norepinephrine $(10-50 \mu \mathrm{M})$ induced increase in synaptic transmission and targeting of BDNF mRNA in dendrites. The increased expression of BDNF in CA3 dendrites following antidepressants or exercise further supports the neurotrophin hypothesis of antidepressants action and confirms that the differential subcellular localization of BDNF mRNA splice variants provides a spatial code for a selective expression of BDNF in specific subcellular districts. This selective expression may be exploited to design more specific antidepressants.

Neuropsychopharmacology (2012) 37, 1600-161 I; doi:I0.1038/npp.2012.5; published online 8 February 2012

Keywords: depression; antidepressants; physical exercise; neurotrophins; hippocampus; dendritic mRNA trafficking

\section{INTRODUCTION}

Brain-derived neurotrophic factor (BDNF) is a neurotrophin that promotes cell survival and death, neuronal maturation, and has a prominent role in long-term synaptic plasticity and psychiatric pathophysiology (Cohen-Cory et al, 2010; Tardito et al, 2006; Yoshii and ConstantinePaton, 2010). The strong correlation between stress or antidepressant treatment and down- or upregulation, respectively, of BDNF in limbic brain regions has led to the 'neurotrophin hypothesis of depression' (Castren, 2004; Duman and Monteggia, 2006). In agreement with this hypothesis, studies in animal

* Correspondence: Dr E Tongiorgi, Department of Life Sciences, BRAIN Centre for Neuroscience, University of Trieste, Via Giorgieri, 5 , Building Q, Trieste 34 I27, Italy, Tel: + 39040558 8724, Fax: + 39040 558 2425, E-mail: tongi@units.it

${ }^{4}$ These authors contributed equally to this work.

${ }^{5}$ In memoriam.

Received 25 July 2011; revised 19 December 2011; accepted 20 December 2011 models and humans have shown that physical exercise that reduces depressive symptoms is accompanied by an increase in brain levels of BDNF (Cotman and Berchtold, 2002; Russo-Neustadt and Chen, 2005).

Antidepressant treatments elicit their effect systemically on CNS with the involvement of prefrontal and cingulate cortex, nucleus accumbens, and amygdala (reviewed in Tanti and Belzung, 2010), as well as the hippocampus. The hippocampus is one of the limbic brain structures where modulation of BDNF cascade can contribute to the actions of antidepressant treatment. Studies on mice with selective BDNF depletion in specific hippocampal subfields have shown that BDNF expression in dentate gyrus (DG), but not in CA1, is essential for the effectiveness of antidepressants by supporting survival and differentiation of newborn DG granule cells. In contrast, the relation between antidepressant action and the expression of BDNF in the CA3 region is still unclear (Adachi et al, 2008; Santarelli et al, 2003).

The neurotrophin hypothesis predicts that in order to provide the biological substrate for an effective antidepressant 
treatment, the newly generated granule cells must be integrated in the hippocampal circuitry, and hence their axons (the mossy fibers) must form new synapses on CA3 dendrites (Castren, 2004; Castren and Rantamaki, 2010; Duman and Monteggia, 2006). On the basis of this prediction, we speculated that antidepressants could also enhance BDNF production in CA3 neurons and, specifically, that BDNF mRNA targeting in dendrites of CA3 neurons may be increased by these drugs. The latter hypothesis is based on the widely accepted notion that local translation of dendritic mRNAs is a mechanism enabling neurons to accumulate specific proteins at synapses where they are functionally required (Steward and Schuman, 2001). The rodent BDNF gene produces 22 different transcripts with unclear function, each composed of one alternatively spliced $5^{\prime}$ UTR exon linked to a common downstream exon containing the coding region with two possible $3^{\prime}$ UTRs (Aid et al, 2007). Transcripts encoding the $5^{\prime}$ exons 1,2 , 4, or 6 altogether represent $95 \%$ of the total BDNF mRNA in rats and mice (Aid et al, 2007) and in the human cortex (Garzon and Fahnestock, 2007; Pruunsild et al, 2007). We previously demonstrated that BDNF mRNA is delivered to distal dendrites in the hippocampus and cortex in response to various stimuli in vitro and in vivo (Capsoni et al, 1999; Righi et al, 2000; Tongiorgi et al, 1997, 2004). More recently, we showed that BDNF transcripts containing exons 1 and 4 are restricted to the soma and proximal dendrites, whereas exon 2 and 6 transcripts extend into the distal dendrites (Chiaruttini et al, 2008; Pattabiraman et al, 2005) and regulate the local dendritic morphology (Baj et al, 2011). On the basis of these findings, we proposed the hypothesis that the differential segregation of BDNF transcripts may provide a 'spatial code' mechanism for the modulation of BDNF availability and function at distinct cellular locations during neuronal plasticity (Tongiorgi, 2008). In this study, we tested if two different antidepressant treatments and physical exercise are able to upregulate selectively BDNF in the dendrites of CA3 neurons.

\section{MATERIALS AND METHODS}

\section{Physical Activity Protocols}

Male C57BL/6J mice (20-25 g, 8-9 weeks old) obtained from the Multidisciplinary Center for Biological Investigation (CEMIB) at State University of Campinas (UNICAMP) were housed at $21^{\circ} \mathrm{C}$ in a $12 \mathrm{~h}$ light/dark cycle, with access to food and water ad libitum. The experimental procedures were approved by the Institutional Committee for Ethics in Animal Experimentation at UNICAMP (CEUA/IB-UNICAMP, 2070-1). Animals were randomly allocated to one of three groups (10 animals per group): (1) Exercise-free access to a mobile running wheel; (2) Lock-Wheel-exposed to a locked running wheel; and (3) Sedentary-without access to running wheel, consisting in a control condition. Animals from the Exercise and Lock-Wheel groups were housed in individual cages $\left(40 \times 32 \times 16 \mathrm{~cm}^{3}\right)$ with free access to a mobile or locked running wheel $(12 \mathrm{~cm}$ diameter; $60 \mathrm{~g})$, respectively. The activity performed by exercising mice on the mobile running wheel was recorded daily for $24 \mathrm{~h}$ by an electronic counter connected to a computer for data storage. Animals had a period of 28 consecutive days of voluntary access to the running wheel. Animals from the sedentary group were individually housed in standard cages $\left(28 \times 18 \times 12 \mathrm{~cm}^{3}\right)$ for the same experimental period (28 days). After the running wheel period, animals were anesthetized with $3 \%$ sodium pentobarbital $(60 \mathrm{mg} / \mathrm{kg}$; i.p.) and killed by transcardial perfusion with $100 \mathrm{ml}$ of heparinized $0.9 \% \mathrm{NaCl}$ (1000 UI heparin $/ 500 \mathrm{ml}$ of $0.9 \% \mathrm{NaCl}$ ), followed by $120 \mathrm{ml}$ of $4 \%$ paraformaldehyde in phosphate buffer $(0.1 \mathrm{M}$, $\mathrm{pH} 7.40$ ), and then brains were extracted and used for in situ hybridization.

\section{Pharmacological Treatment Protocols}

Male Sprague-Dawley rats (6 weeks old at the beginning of treatment) (Charles River, Calco, Italy) were treated with vehicle (water), fluoxetine (FLX), or reboxetine (RBX) delivered in drinking water at $10 \mathrm{mg} / \mathrm{kg}$ rat weight per day, verifying that the volume that the rats drunk was the same for vehicle and antidepressants groups. Experiments complied with guidelines for use of experimental animals of European Community Council Directive 86/609/EEC and the average water intake per day for each cage (two rats) was recorded for 4 days before starting and throughout the treatment, and the drug solutions were changed every 2 days according to animals' weight, as reported previously (Dow et al, 2005; Tardito et al, 2009). Rats were divided into three experimental groups with 12 animals per group: control (water), 2 weeks treatment with FLX, or 2 weeks treatment with RBX.

\section{Cell Cultures and Treatments}

Rat hippocampal neurons used for electrophysiological and mRNA targeting experiments were cultured 8-9 days after plating, as described previously (Tongiorgi et al, 1997). RNAi pool specific for exon 6 was generated from the transcript of BDNF by PCR amplification of a 210-nt-long segment $(167 \mathrm{nt}+$ the T7-RNA polymerase sequence at the $5^{\prime}$ end) with low levels of homology to other genes and high scores as targets for silencing as evaluated with the software 'siRNA Target finder' (Ambion). Primer sequences targeting BDNF rat exon 6 (GenBank: EF125680.1) are as follows: exon 6-T7 forward, $5^{\prime}$-GCGTAATACGACTCACTATAGGGC GGCTTGGAGAAGGAAAC- ${ }^{\prime}$; and exon 6-T7 reverse, 5'-GC GTAATACGACTCACTATAGGGGAGTCACATTGTTGTCA CGC-3' (Proligo). To obtain synthetic siRNA pool, doublestranded RNA was synthesized using T7-RNA polymerase with the corresponding mixture kit (Ambion) and digested with RNaseIII (Ambion), which generates oligonucleotides of 12-15 base pairs in length, which have been shown to be just effective as the longer Dicer 22-mer products. Detailed description of primers and analysis of siRNA efficiency was reported previously (Baj et al, 2011). We used the scramble siRNA duplex (Ambion), which has no effect on neuronal morphology and survival, as a control. Primary hippocampal neurons were transfected with the siRNA pool for exon 6 BDNF or scramble siRNA at 6 days in vitro using Lipofectamine 2000 (Invitrogen) following the manufacturer's recommendations and treated with drugs 3 days later.

Drugs were applied to hippocampal cultures via bath superfusion using a three-way tap system. For serotonin 
(5-HT) and norepinephrine (NE) (Tocris), particular care was taken to minimize compound oxidation (Hughes and Smith, 1978). A stock in distilled water was made immediately before the experiment and added to the bath solution to reach the final concentration.

\section{In Situ Hybridization}

Hippocampal neurons were analyzed by in situ hybridization as described previously (Tongiorgi et al, 1997). In situ hybridization on free-floating, $40-\mu \mathrm{m}$ coronal brain sections cut at the level of dorsal hippocampus was performed as described previously (Chiaruttini et al, 2008; Tongiorgi et al, 1998). Probe specificity for the CDS or for exon 4 or 6 was demonstrated previously (Chiaruttini et al, 2008). Hybridization was followed by high stringency washes with $0.01 \times$ sodium saline citrate buffer containing $0.1 \%$ Tween20 (SSCT) at $60^{\circ} \mathrm{C}$. All in situ hybridizations on brain sections from treated animals were conducted in contemporary with brain sections from control animals. The use of non-radioactive in situ hybridization using digoxigeninlabeled probes for semiquantitative evaluation of the in situ staining has been previously validated by us and other laboratories (Palop et al, 2011; Swanger et al, 2011; Tongiorgi et al, 2004).

\section{Immunohistochemistry}

For total BDNF immunohistochemistry, brain slices were blocked in PBS solution containing $0.01 \%$ Triton X-100, $2 \%$ BSA (Sigma), and $2 \%$ normal goat serum for $1 \mathrm{~h}$, and then were incubated overnight at $4{ }^{\circ} \mathrm{C}$ with the monoclonal mouse anti-BDNF antibody $\mathrm{mAb}$ (1:1000; Promega). To confirm the staining pattern, a few sections were incubated in parallel with either rabbit anti-BDNF pAb sc-546 (N-20) from Santa Cruz $(1: 200)$ or the anti-BDNF mouse mAb from Sigma $(1: 50)$. Anti-mouse or anti-rabbit secondary antibodies were conjugated with Alexa-Fluor488 (1:1000; Invitrogen). Fluorescent signals were detected using a Nikon C1Si laser scanning confocal microscope and quantified using ImageJ (NIH).

\section{Quantitative Imaging Analysis and Statistics}

Non-radioactive in situ hybridization was analyzed with a Nikon E800 microscope ( $\times 60$ magnification) and a CCD camera (Nikon ADX-1200). For measures on brain sections, images were captured with a standardized illumination using the procedure described previously (Tongiorgi et al, 2004) and analyzed with the program Image-ProPlus 4.0 (Media Cybernetics). We measured the relative thickness of stratum pyramidale, stratum radiatum, stratum lacunosum molecularis, molecular layer, and granule cell layer in coronal sections used for in situ staining. For comparison, we also performed the same measurements on images collected from brain atlases on the website http://brainmaps.org, and found that for both rat and mouse, the relative thickness is a robust and constant measure because it did not vary across the different coronal sections collected along the anteroposterior axis of the same animal (Supplementary Figure 1). For measures on cultured neurons, the function 'trace' of the image analysis program
Image-ProPlus was used to measure the maximal distance of dendritic labeling (MDDL) as described previously (Tongiorgi et al, 1997), with the following modification: dendrites were traced up to the point at which the in situ labeling was no longer clearly distinguishable from the background that was set as threshold. Neurons were randomly sampled from each culture discarding bipolar neurons and around 50 apical dendrites were measured for each treatment (three independent experiments). Individual preparations were coded and analyzed in a blinded manner.

\section{Electrophysiological Recordings}

Tight-seal whole-cell recordings (Hamill et al, 1981) were obtained at room temperature $\left(22-24{ }^{\circ} \mathrm{C}\right)$ from visually identified large (approx. average diameter $25 \mu \mathrm{m}$ ) triangular-shaped hippocampal neurons, 9 days in culture, presumed to be pyramidal cells. The bath solution contained the following (in $\mathrm{mM}$ ): $145 \mathrm{NaCl}, 4 \mathrm{KCl}, 1.5$ $\mathrm{CaCl}_{2}, 1 \mathrm{MgCl}_{2}, 10 \mathrm{~N}$-2-hydroxyethylpiperazine- $N^{\prime}$-2-ethanesulfonic acid (HEPES), and 10 glucose. Patch pipettes had tip resistance of 3-4 M $\Omega$ and were filled with the following pipette solution (in $\mathrm{mM}$ ): $120 \mathrm{~K}$-gluconate, $20 \mathrm{KCl}, 10$ HEPES, $9 \mathrm{NaCl}, 1 \mathrm{MgCl}_{2}$, and $2 \mathrm{Mg}_{2} \mathrm{ATP}$. Under voltageclamp configuration, spontaneous post-synaptic currents (sPSCs) were recorded ( $-60 \mathrm{mV}$ holding potential), made up of a mixed population of inhibitory and excitatory PSCs, manifested as transient inward currents in our recording conditions. Responses were amplified with an EPC-7 amplifier (List Medical) linked to a PC controlled by the pCLAMP software 7.0 (Axon Instruments). Recordings were sampled every $0.03 \mathrm{~ms}$ and filtered at $2 \mathrm{kHz}$. Capacitance neutralization and series resistance compensation were applied while monitoring the voltage response to a current step at high time resolution. For data analysis, the Origin 7.0 software (Microcal Software) was used routinely. All values are expressed as means \pm standard error (SE).

\section{Statistical Analysis}

The Student's $t$-test was used for two-sample comparisons. For multiple sample comparisons, two-way ANOVA was performed, followed by Holm-Sidak post-test using the SigmaStat software (Systat).

\section{RESULTS}

\section{Effect of Exercise on Total BDNF mRNA Expression and Dendritic Targeting}

Since physical activity has a recognized antidepressant effect, both experimentally and in human patients with major depression (Bjornebekk et al, 2005; Russo-Neustadt et al, 1999; Trivedi et al, 2006; Vaynman et al, 2004), we decided to evaluate the role of physical activity on BDNF expression in the hippocampus of exercising, lockwheel, and sedentary mice (see Materials and methods) after 4 weeks of treatment. Exercising animals ran an average distance of approximately $4.80 \pm 0.56 \mathrm{~km}$ per day and accessed the running wheel preferentially at night 
(1900-0700 hours). The local expression of BDNF in CA1, DG, and CA3 hippocampal subregions was analyzed by in situ hybridization, using a probe common to all BDNF mRNAs (total BDNF; Figure 1a). Densitometric analysis of in situ hybridizations showed a trend towards increased levels of BDNF mRNA in the soma of CA1 $(+20 \%)$ and DG $(+16 \%)$ neurons without reaching a statistical significance (Figure $1 \mathrm{~b}, \mathrm{c}, \mathrm{e}$, and $\mathrm{f}$ ), while in the CA3 stratum pyramidalis, which contains the neuronal somata, the expression of total BDNF mRNA was significantly increased in exercising animals, but not in the lock-wheel group with respect to the sedentary control group $(+22 \% ; p<0.05$; Figure 1g). Remarkably, in CA3 stratum lucidum and radiatum, which contains the apical dendrites of CA3 neurons as well as the axons from CA3, DG, and extrahippocampal neurons, we observed a significant increase in BDNF mRNA levels $(+23 \% ; p<0.05)$ with respect to the same laminas in sedentary animals (Figure 1d and g). To distinguish between the possibility that experimental treatments may cause extension of longer dendrites and therefore BDNF being detected at a farther distance from soma, $v s$ BDNF being translocated to a more distal site on a dendrite, we performed a specific analysis of the relative thickness of somatic and dendritic layers in all sections processed for in situ hybridization. We confirmed that no gross morphological variations occurred in hippocampal dendritic layers following antidepressant treatments (Supplementary Figure 1). In conclusion, as axons are devoid of BDNF mRNA (Tongiorgi et al, 2004), these results indicate that exercise produces a specific increase of BDNF mRNA in the somata and apical dendrites of CA3 neurons.

\section{Effect of Antidepressants on Total BDNF mRNA Expression and Dendritic Targeting}

To determine if the selective increase of BDNF mRNA observed in CA3 dendrites was a common feature of both exercise and antidepressant drugs, experimental rats were treated for 2 weeks with the selective 5-HT reuptake inhibitor FLX or the selective NE reuptake inhibitor RBX. Total BDNF mRNA was revealed by in situ hybridization (Figure 2a and $\mathrm{b}$ ) and quantitative analysis showed that BDNF mRNA expression was significantly increased in the two antidepressants groups, with respect to the control group in the somata of CA1 $(+24.2 \% \mathrm{FLX} ;+28.2 \% \mathrm{RBX}$; $p<0.001)$, DG $(+28.4 \%$ FLX; $+30.9 \%$ RBX; $p<0.01)$, and CA3 ( + 38.7\% FLX; + 48.2\% RBX; $p<0.01$ ) neurons (Figure $2 \mathrm{c}$ and $\mathrm{d}$ ). In addition, a strong increase in BDNF mRNA levels was found in CA3 stratum lucidum for both FLX and RBX $(+61.3 \%$ FLX; $+63.4 \%$ RBX; $p<0.01$; Figure $2 b$ and e). These treatments had no effects on the relative thickness of the hippocampal layers containing the dendrites, suggesting that the observed in situ signal increase was not accounted for by gross morphological changes (Supplementary Figure 1). Thus, FLX and $\mathrm{RBX}$, besides inducing a general increase of BDNF in the neuronal somata in the whole hippocampus, were able a

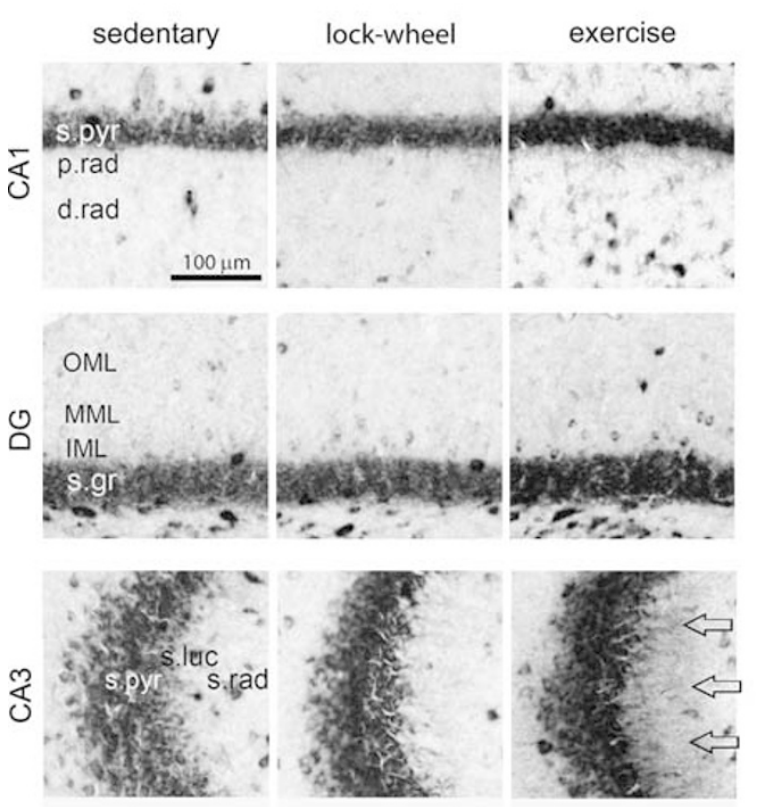

b

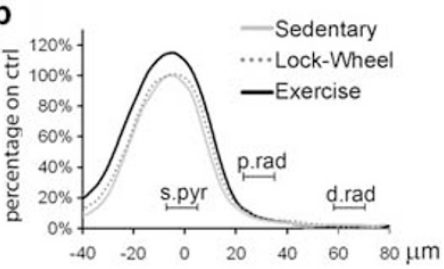

C

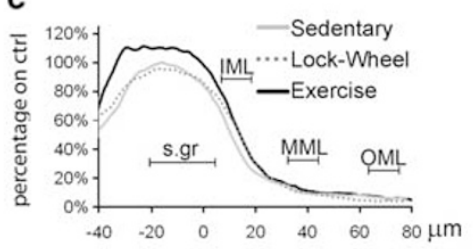

d

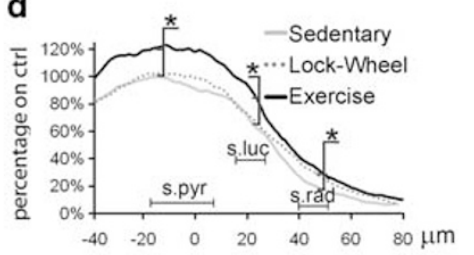

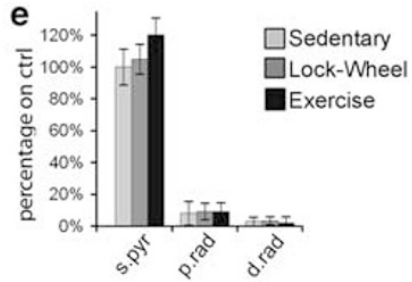

f
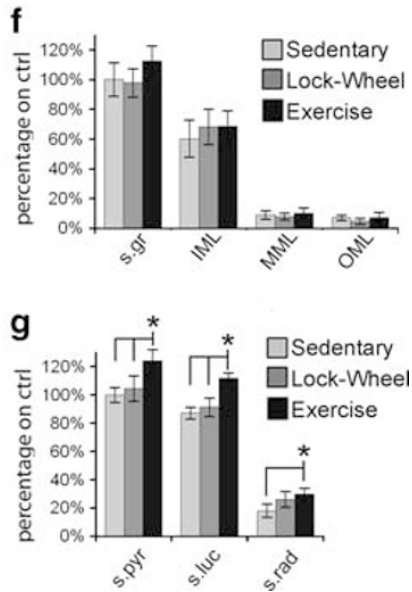

Figure I Effects of physical exercise on local brain-derived neurotrophic factor (BDNF) mRNA expression in mouse hippocampus. (a) High-magnification pictures of the in situ hybridization for BDNF mRNA in mouse hippocampal CAI, dentate gyrus (DG), and CA3 regions showing staining in the stratum pyramidale (CAI, CA3) and granularis (DG). Labeled dendrites are visible only in the CA3 stratum lucidum and radiatum (empty arrows). (b-d) Line graphs show densitometric analysis of the laminas containing dendrites, expressed as percentage of the staining measured in control animals (=100\%). The distance is expressed in $\mu \mathrm{m}$ from the point of emergence of the apical dendrites from the soma $(=0 \mu \mathrm{m})$. (e-g) Bar graphs show pooled data calculated by grouping intervals of $20 \mu \mathrm{m}$ from the same hippocampal subregion. Each bar represents the mean \pm SE of six animals per group. *p $<0.05$. s.pyr, stratum pyramidale; p.rad, proximal radiatum; d.rad, distal radiatum; s.gr, stratum granularis; IML, inner molecular layer; MML, medial molecular layer; OML, outer molecular layer; s.luc, stratum lucidum; and s.rad, stratum radiatum. 
a

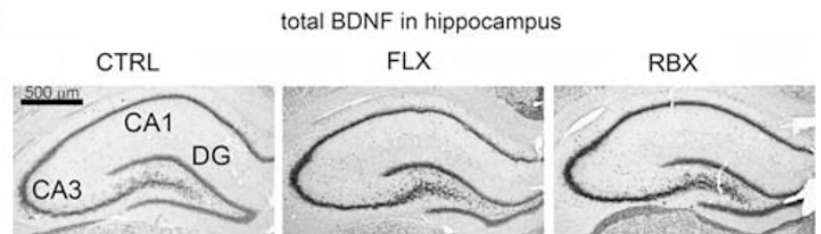

b
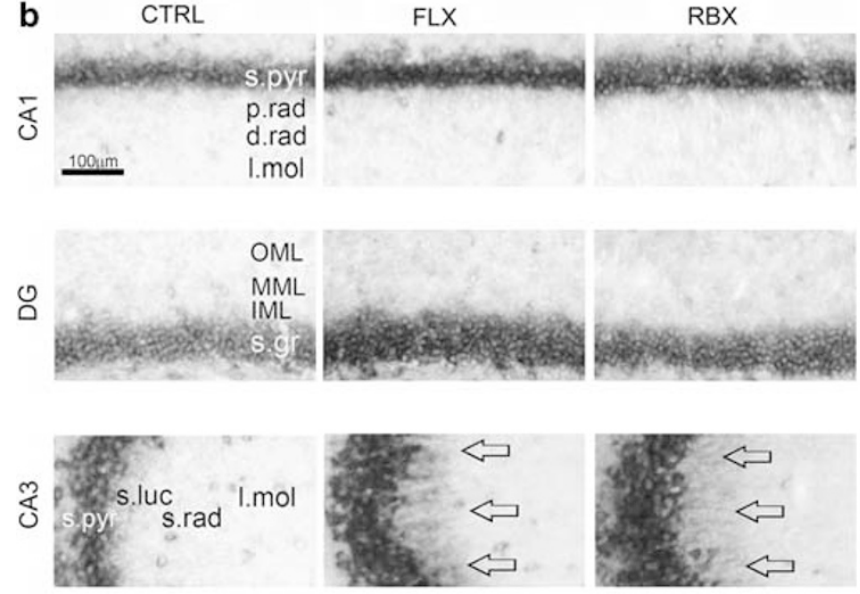

C

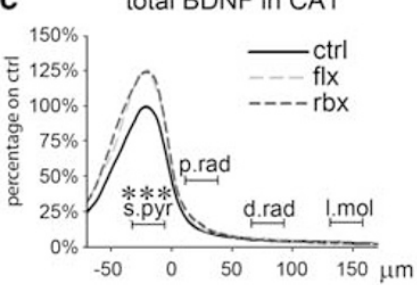

d

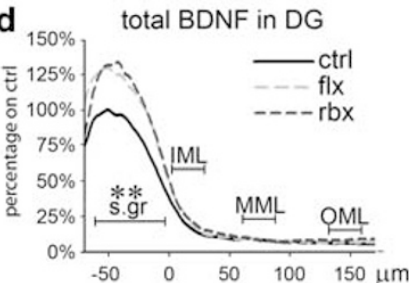

e

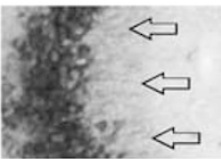

total BDNF in CA1
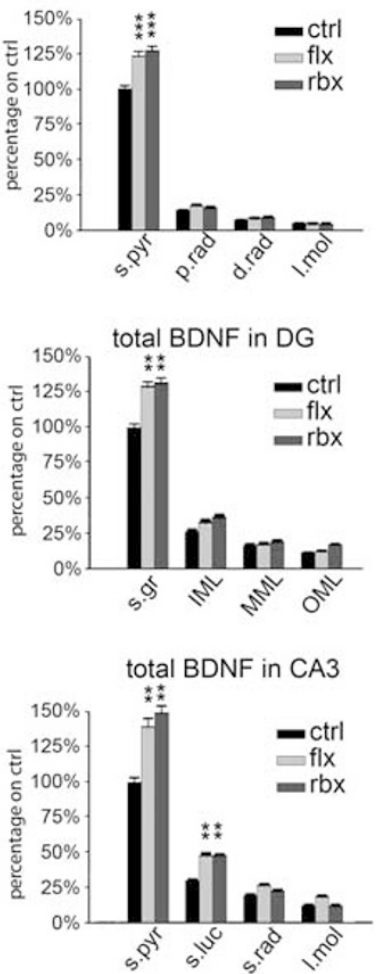

Figure 2 Effects of antidepressants on local brain-derived neurotrophic factor (BDNF) mRNA expression in rat hippocampus. (a) Representative images of in situ hybridizations for total BDNF mRNA in dorsal rat hippocampus sections from animals treated with vehicle (CTRL), I0 mg/kg fluoxetine (FLX), or $10 \mathrm{mg} / \mathrm{kg}$ reboxetine (RBX). (b) High-magnification pictures from CAI, dentate gyrus (DG), and CA3 areas. Arrows indicate labeling of dendritic field in CA3. (c-e) Densitometric analysis of the dendritic labeling for total BDNF mRNA in CAI, DG, and CA3 expressed as gray level, a function of the distance from the cell soma (in $\mu \mathrm{m}$ ) in control fluoxetine- and reboxetine-treated animals. Data are the means \pm SE of $4-6$ animals; $* * p<0.0$ I, **** $p<0.00$ I. Neuroanatomical subregions are indicated as in Figure I.

(similarly to the effect of exercise) to selectively upregulate BDNF mRNA in the apical dendrites of CA3 neurons.

\section{Local Increase of BDNF Protein in CA3 Stratum Lucidum Following Antidepressants}

We next investigated if the increase in total BDNF mRNA observed in CA3 stratum lucidum and stratum radiatum following physical activity or antidepressant treatments was paralleled by a local increase in BDNF protein. Immunohistochemistry was performed on brain sections with a monoclonal anti-BDNF antibody $(1: 1000$; Promega) (Figure 3). A few control sections were incubated in parallel with either rabbit pAb anti-BDNF from Santa Cruz $(1: 200)$ or the anti-BDNF mouse $\mathrm{mAb}$ from Sigma $(1: 50)$ obtaining similar staining patterns (data not shown). Physical activity for 4 weeks, as well as FLX or RBX treatments for 2 weeks, increased BDNF protein immunofluorescence as shown by a semiquantitative densitometric analysis of brain sections (Figure $3 a$ and $b$ ). With each of these three treatments, it was possible to observe a robust increase in immunostaining for BDNF in CA3 stratum pyramidale and lucidum with respect to control animals (Figure 3a-d). Additional increase in BDNF immunofluorescence could be observed in DG for exercise and RBX (Figure 3a and b). Treatment with FLX or RBX also induced a clear increase within the CA3 stratum radiatum for both treatments
(Figure $3 b$ and $d$ ), which parallels the observed increase of BDNF mRNA in CA3 apical dendrites.

\section{Localization of BDNF Exon 4 and 6 Transcripts in Exercise or Antidepressant-Treated Animals}

Previous studies identified the exon 6 BDNF splice variant as the major BDNF transcript in dendrites (Chiaruttini et al, 2008). To investigate directly the involvement of exon 6 BDNF splice variant in the response to exercise or antidepressants, we analyzed the subcellular localization of this mRNA, in comparison with that of the most abundant transcript with a somatoproximal localization, that is, the exon 4 BDNF splice variant. In mice, exon 4 variant was expressed in the somata of all hippocampal areas of sedentary and locked-wheel animals (Figure 4a, c, e, and g). Following 4 weeks voluntary exercise, exon 4 expression was substantially unchanged with the only exception of a slight (nonsignificant) increase in the soma of CA1 neurons (Figure 4c) and a significant increase $(p<0.05)$ in proximal dendrites of DG neurons, which was restricted to the inner molecular layer and the beginning of the medial molecular layer (Figure 4e). In contrast, exon 6 variant was significantly increased by exercise in the somata of CA1 and CA3 hippocampal areas $(p<0.05)$, and was significantly upregulated $(p<0.05)$ into the dendrites in CA1 stratum radiatum and DG inner molecular layer, and 

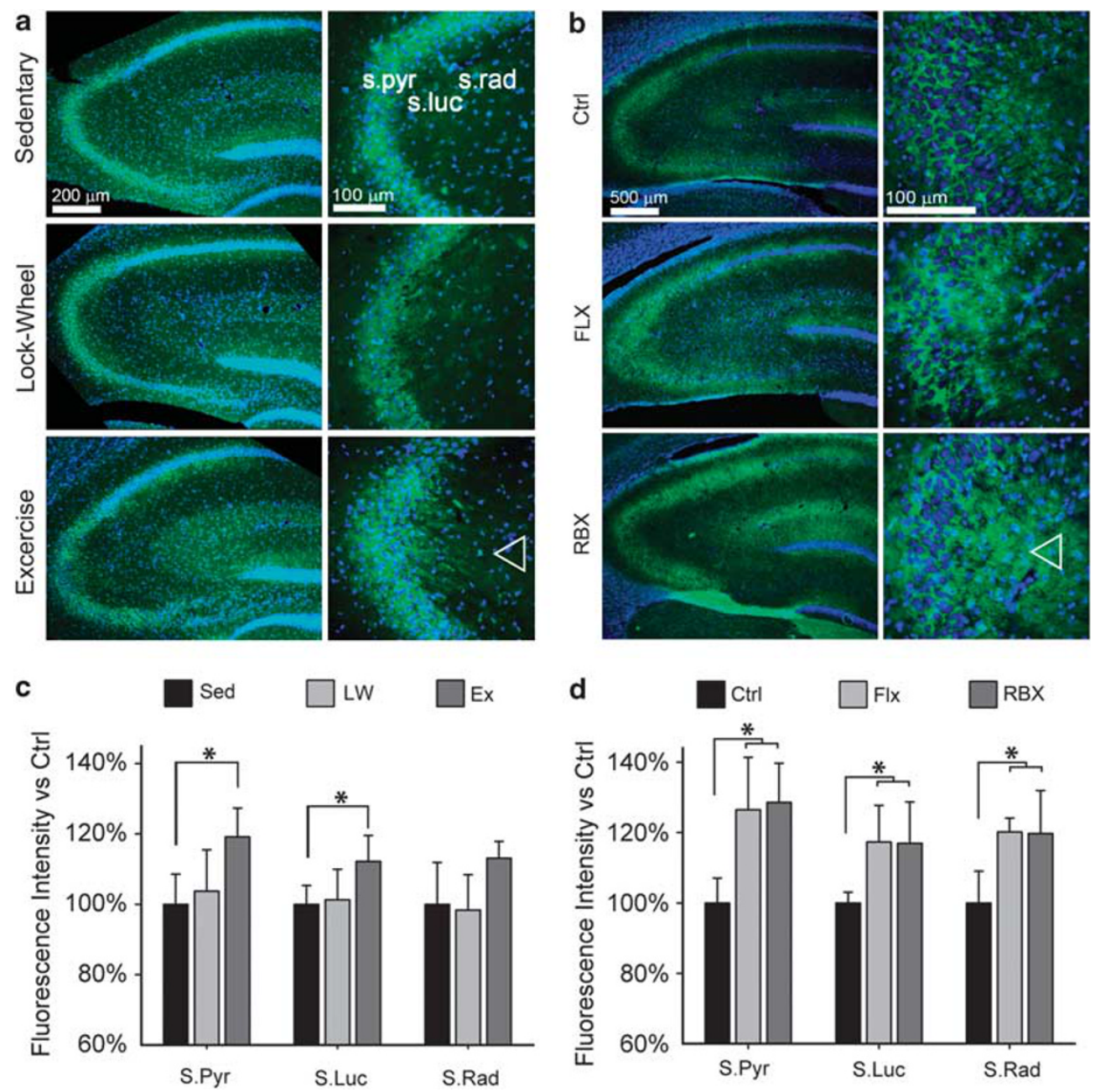

Figure 3 Effects of exercise or antidepressants on local brain-derived neurotrophic factor (BDNF) protein expression in rat hippocampus. (a, b) AntiBDNF immunofluorescence (green, with Hoechst-counterstained nuclei in blue) in the hippocampus of animals from (a) sedentary, exercise, or lock-wheel groups; or (b) treated with vehicle (Ctrl), $10 \mathrm{mg} / \mathrm{kg}$ antidepressant fluoxetine (FLX), or reboxetine (RBX). Right panels show enlarged CA3 fields from the same sections. Arrowheads in the CA3 region in (a) and (b) point to increased BDNF immunofluorescence in the stratum lucidum and radiatum. (c, d) Densitometric quantification of BDNF in CA3 subregions of animals in the different conditions ( $n=4$, each group) in comparison with BDNF fluorescence staining quantified in CA3 from control group. The differential staining visible in the figure does not affect the results in the densitometry because the different treatments were normalized on their internal controls. Data are the means \pm SD of four sections; * $p<0.05$. s.pyr, stratum pyramidale; p.rad, proximal radiatum; d.rad, distal radiatum.

was strongly increased $(p<0.01)$ in CA3 stratum lucidum (Figure $4 \mathrm{~b}, \mathrm{~d}, \mathrm{f}$, and $\mathrm{h}$ ).

In rats, expression of exon 4 BDNF mRNA was also localized in cell bodies of all hippocampal areas in control animals, and was unchanged in the soma of CA1 and DG following antidepressant treatments with respect to the control group (Figure 5a, c, and e). In contrast, in CA3 stratum pyramidale, BDNF staining showed a small but significant reduction $(-12 \% ; p<0.05)$ in the in RBX-treated animals (Figure $5 \mathrm{~g}$ ). Moreover, irrespective of treatment, we found no staining for exon 4 BDNF mRNA in laminas containing the apical dendrites emerging from the different hippocampal subfields (Figure $5 c$, e, and g). Conversely, the exon 6 BDNF mRNA (Figure 5b, d, f, and h) showed a strong increase in the stratum pyramidale of CA3 neurons ( $+63 \%$ after FLX and $+76 \%$ after RBX; Figure $5 \mathrm{~b}$ and $\mathrm{h}$ ), but no change in CA1 and DG neuronal somata (Figure 5b, $\mathrm{d}$, and $\mathrm{f}$ ). Regarding the laminas containing dendrites, we found in the CA3 region a significant increase in mRNA signal in the stratum lucidum, with both treatments $(+77 \%$ after FLX and $+88 \%$ after RBX; $p<0.001)$, and in stratum radiatum of slices from animals treated with RBX $(+32 \%$; $p<0.001$; Figure $5 \mathrm{~b}$ and e). These data are remarkably similar to the results obtained in exercising animals, suggesting that the exon 6 variant can account for most of the staining observed for total BDNF mRNA in the CA3 region.

\section{5-HT and NE Effects on BDNF mRNA Dendritic Targeting}

Increased central serotonergic and noradrenergic synaptic transmission is a common feature that physical exercise shares with the effects of antidepressants FLX and RBX (Ivy et al, 2003; Ma, 2008). Accordingly, we sought to verify if the two neurotransmitters $5-\mathrm{HT}$ and NE were able to induce 
a

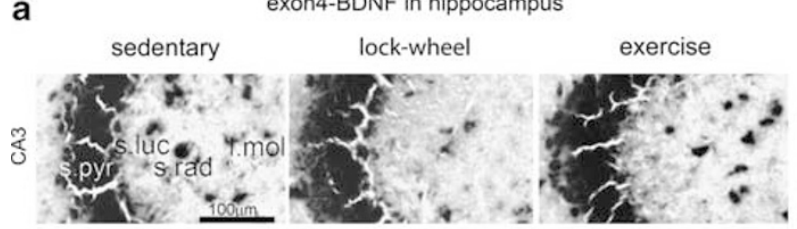

C

exon4-BDNF in CA1
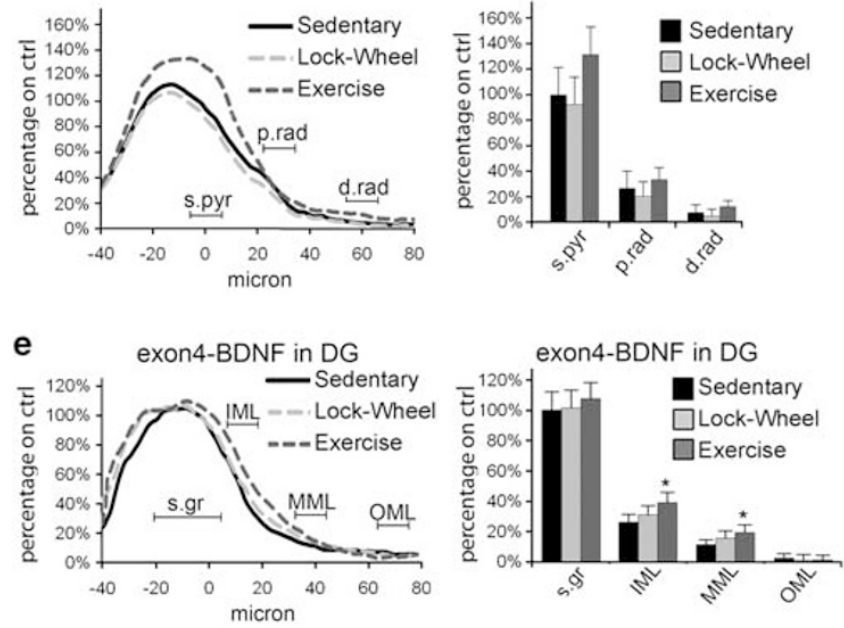

g

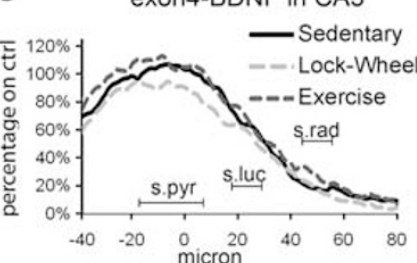

exon4-BDNF in CA1

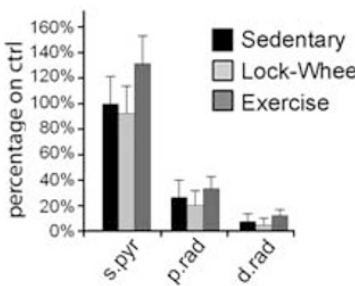

exon4-BDNF in CA3

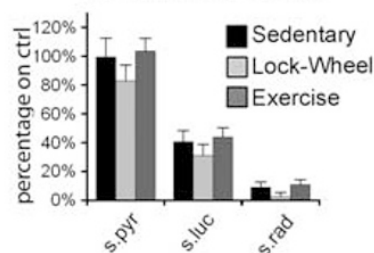

b

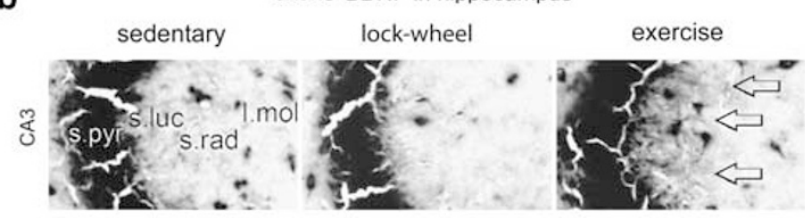

d

exon6-BDNF in CA1

exon6-BDNF in CA1
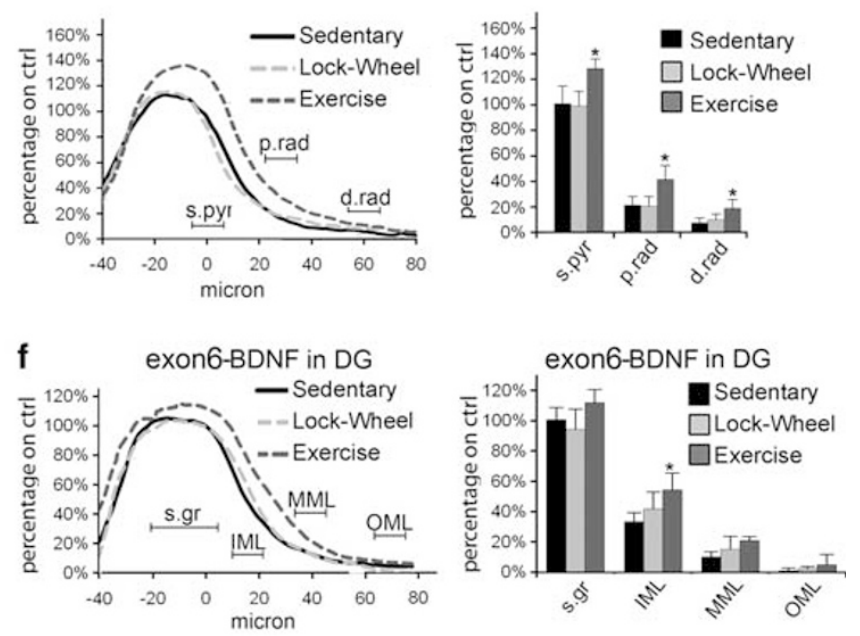

h

exon6-BDNF in CA3

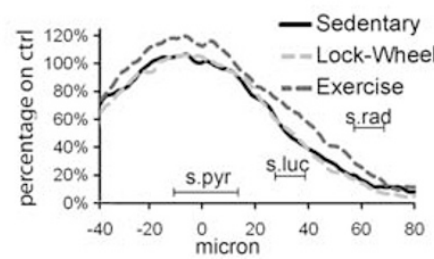

exon6-BDNF in CA3

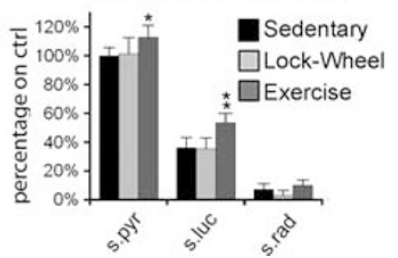

Figure 4 Effects of exercise on exons 4 and 6 brain-derived neurotrophic factor (BDNF) mRNA expression in rat hippocampus. (a, b) High magnification of CA3 area in coronal brain sections at the level of the dorsal hippocampus showing localization of (a) exon 4 BDNF transcripts or (b) exon 6 BDNF transcripts in control sedentary mice, or accessing a lock-wheel or doing exercise on a running wheel. (c-h) Densitometric analysis of the dendritic labeling of exon 4 BDNF transcripts (c,e,g) or exon 6 BDNF $(d, f, h)$ in CAI, dentate gyrus (DG), and CA3 expressed as gray level, a function of the distance from the cell soma (in $\mu \mathrm{m}$ ). Data are the means \pm SE of $3-4$ animals, ${ }^{*} p<0.05$; $* * 00.01$. Neuroanatomical subregions are indicated as in Figure I. Scale bar in (a) $=500 \mu \mathrm{m}$ and in (b) $=100 \mu \mathrm{m}$.

BDNF mRNA targeting in dendrites. Using in situ hybridization to detect endogenous total BDNF mRNA in unstimulated hippocampal neurons cultured for 9 days in vitro (Figure 6a), we found that BDNF mRNA was localized in the soma and proximal dendrites. The measure of the MDDL was taken as the point at which the in situ hybridization signal reached the background level (Figure 6b), which corresponded to a distance of $35 \mu \mathrm{m}$ from the soma for total BDNF mRNA in control cultures (Figure 6c). We first used a depolarization protocol consisting in a bath application of $10 \mathrm{mM} \mathrm{KCl}$ that was well known to cause increased localization of BDNF mRNA to distal dendrites (Tongiorgi et al, 1997), and after $3 \mathrm{~h}$, we found an average MDDL from the soma of $80 \mu \mathrm{m}$ (Figure 6a and c). Incubation for $3 \mathrm{~h}$ with concentrations of 10 or $50 \mu \mathrm{M} 5-\mathrm{HT}$ or NE produced, in both cases, a significant increase in dendritic targeting of BDNF mRNA (Figure 6a and c). MDDL values were $45 \pm 4.2$ and $64 \pm 3.5 \mu \mathrm{m}$ for 10 and $50 \mu \mathrm{M} 5-\mathrm{HT}$, respectively, and $52 \pm 3.9$ and $73 \pm 3.2 \mu \mathrm{m}$ for 10 and $50 \mu \mathrm{M} \mathrm{NE}$, respectively (Figure $6 \mathrm{c}$ ). The exon 6- containing transcript largely accounted for the observed increase in dendritic labeling for BDNF induced by $5-\mathrm{HT}$ and NE because a siRNA directed specifically against this BDNF variant reduced the MDDL to background level (Figure 6c). Interestingly, siRNA exon 6 only partially reduced the increase in MDDL for total BDNF mRNA induced by $\mathrm{KCl}$, indicating that additional exons are involved in this response (Figure $6 \mathrm{c}$ ). Figure $6 \mathrm{~d}$ shows MDDL quantification of the in situ hybridization against the exon 6 BDNF variant, which further demonstrated that this variant is targeted in dendrites in response to $\mathrm{KCl}, 5-\mathrm{HT}$, and NE, similarly to total endogenous mRNA, and that this signal is almost completely abolished by the siRNA against exon 6. These results obtained in vitro suggest a direct link, in hippocampal neurons, between activation of the serotonergic and noradrenergic pathways and BDNF mRNA dendritic localization and further demonstrates the key role of the exon 6 variant. However, as dendritic targeting of BDNF mRNA is known to be induced by cellular depolarization (Tongiorgi et al, 1997), we checked if 5-HT 
a

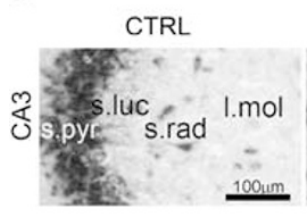

C
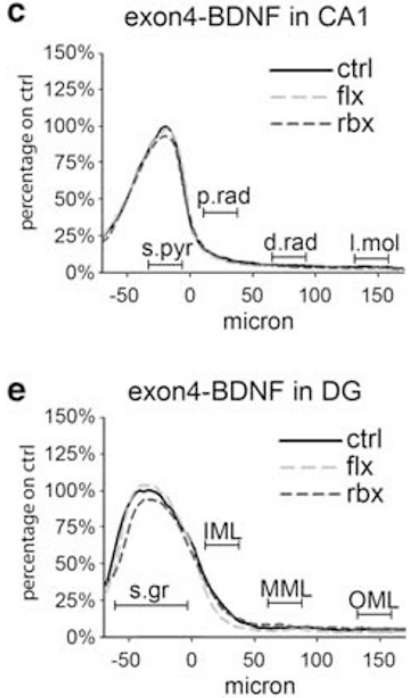

g

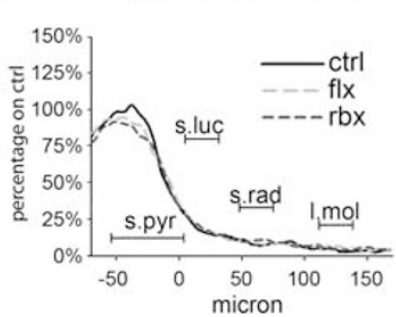

FLX

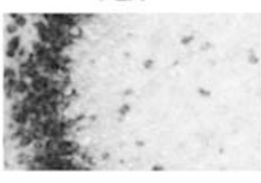

RBX

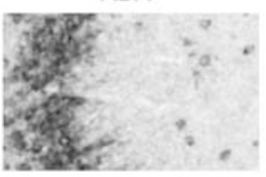

b

exon6-BDNF in hippocampus

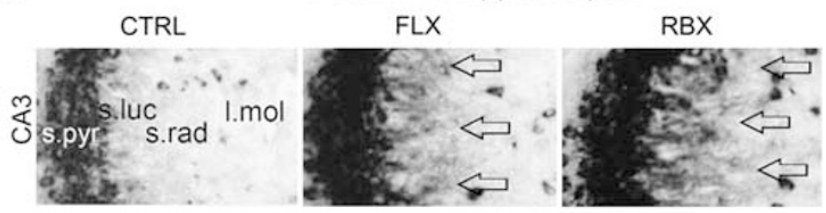

d exon6-BDNF in CA1

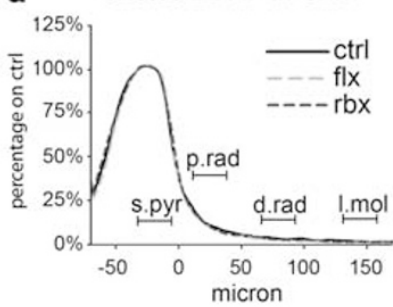

f exon6-BDNF in DG

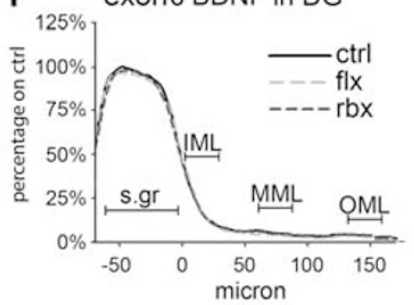

h

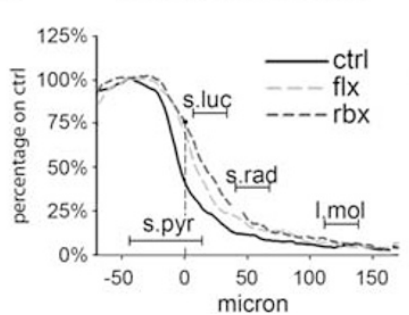

exon6-BDNF in CA1

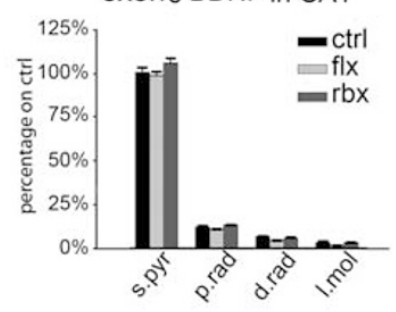

exon6-BDNF in DG

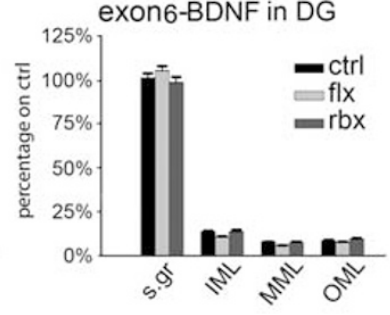

exon6-BDNF in CA3

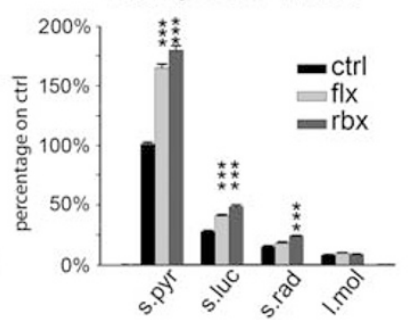

Figure 5 Effects of antidepressants on exons 4 and 6 brain-derived neurotrophic factor (BDNF) mRNA expression in rat hippocampus. (a, b) High magnification of CA3 area in coronal brain sections at the level of the dorsal hippocampus showing localization of (a) exon 4 BDNF transcripts or (b) exon 6 BDNF transcripts in control condition (CTRL) or following $10 \mathrm{mg} / \mathrm{kg}$ fluoxetine (FLX) or reboxetine (RBX) treatments. (c-h) Densitometric analysis of the dendritic labeling of exon 4 BDNF transcripts (c, e, g) or exon 6 BDNF $(d, f, h)$ in CAl, DG, and CA3 expressed as gray level, a function of the distance from the cell soma (in $\mu \mathrm{m}$ ). Data are the means \pm SE of $4-6$ animals; $* * * 0.01$; $* * * *<0.00$ I. Neuroanatomical subregions are indicated as in Figure I. Scale bar in $(\mathrm{a})=500 \mu \mathrm{m}$ and in $(\mathrm{b})=100 \mu \mathrm{m}$.

or $\mathrm{NE}$ at $50 \mu \mathrm{M}$, which we observed to be the concentration more efficient to induce BDNF mRNA dendritic targeting, could also increase the frequency of sPSCs. Patch-clamp recordings in whole-cell configuration on rat hippocampal cells in culture revealed that in control conditions, the mean event amplitudes and frequencies of spontaneous sPSCs were $27 \pm 4 \mathrm{pA} \quad(n=8)$ and $1.28 \pm 0.6 \mathrm{~Hz} \quad(n=9)$, respectively. Both $50 \mu \mathrm{M} 5-\mathrm{HT}$ and $50 \mu \mathrm{M}$ NE, bath applied for the entire duration of the recording, significantly increased the frequency of sPSCs $(p<0.05)$ measured 5 min after drug application (Figure 6d and e). In particular, a $180 \pm 17 \%$ increase in mean event frequency was observed in 5-HT $(n=4)$, whereas a $394 \pm 118 \%$ increase was observed in NE $(n=5 ; p<0.05$; Figure $6 \mathrm{~d}$ and e). A $24 \pm 16 \%$ increase in sPSCs amplitude was observed in 5-HT $(n=4)$, whereas an $11 \pm 9 \%$ increase was observed in NE $(n=5 ; p>0.05)$. In both cases such changes were not significant. The frequency of spontaneous sPSC, which are generated by action potential-dependent as well as spontaneous quantal release, should mainly reflect random firing of local neurons, and thus provides an index of how 5-HT or NE boosted local neuronal network excitability. We must note that with the cell culturing conditions used, we are unable to distinguish the hippocampal neurons deriving from either CA1 or CA3, and that we may be recording from CA1 neurons. In conclusion, these findings suggest that the mechanisms through which $5-\mathrm{HT}$ or $\mathrm{NE}$ (at $50 \mu \mathrm{M}$ concentration) stimulate BDNF mRNA targeting could involve a change in neuronal excitability, synaptic activity, or both.

\section{DISCUSSION}

In this study, we show that physical activity, as well as the antidepressants FLX and RBX, produces a general increase in BDNF mRNA and protein in the soma of hippocampal 


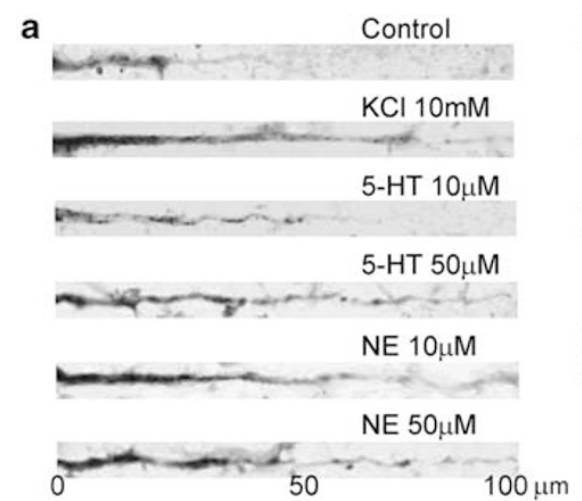

C

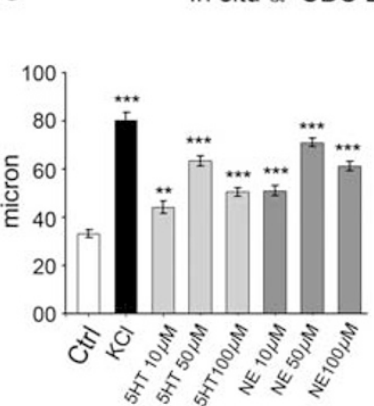

e
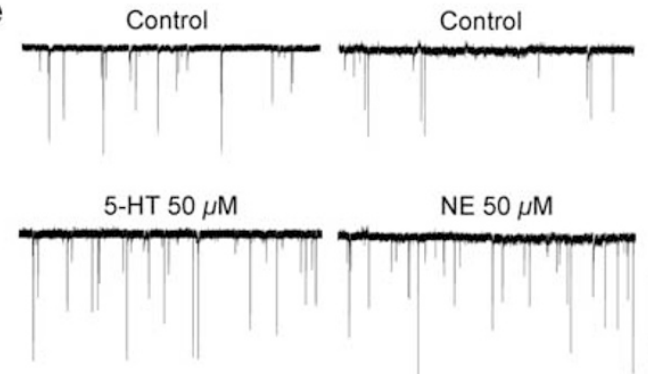

SiRNA exon6

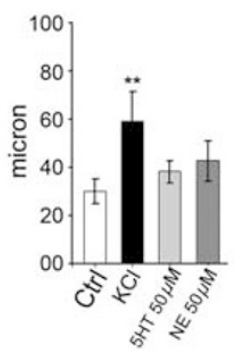

d

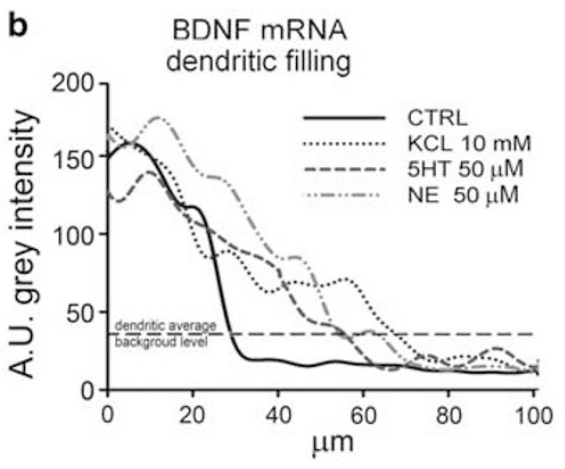

d $\quad$ In situ $\alpha$-exon6

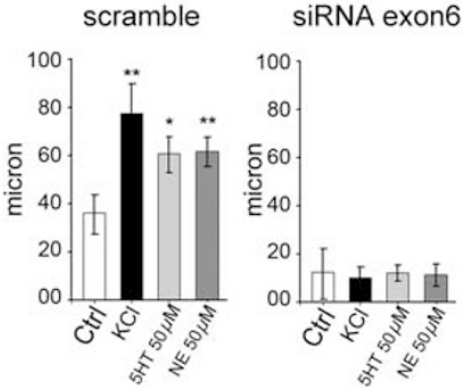

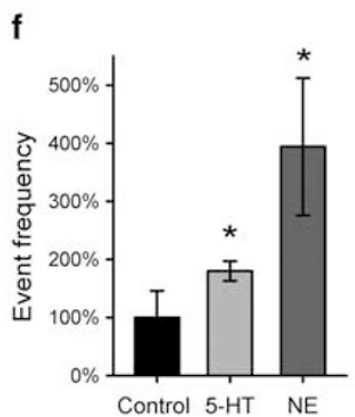

Figure 6 Analysis of serotonin (5-HT) and norepinephrine (NE) effects on brain-derived neurotrophic factor (BDNF) mRNA localization and spontaneous synaptic electrical activity in cultured rat hippocampal neurons. (a) Representative pictures of in situ hybridization for total BDNF mRNAs from nine div rat-cultured hippocampal neurons treated with increasing concentrations of 5-HT or NE. The images show the first $100 \mu \mathrm{m}$ of apical dendrites whose pictures were linearized using the Imagej-straighten plugin. (b) Densitometric analysis of the pictures shown in (a) at the indicated distances (expressed in $\mu \mathrm{m}$ ) from soma, showing the point at which the in situ hybridization signal reached the background level (ie at densitometric arbitrary units $(A U)=35$ ) that was used to calculate the maximal distance of dendritic labeling (MDDL) in each case. (c) MDDL for total BDNF mRNA in hippocampal neuronal cultures treated as indicated. (d) MDDL for exon 6 BDNF mRNA variants in hippocampal neuronal cultures treated as indicated. (e) Examples of spontaneous synaptic currents in nine div-cultured neurons recorded under whole-cell patch-clamp technique at a holding potential of - $60 \mathrm{mV}$, in control conditions and after addition of 5-HT or NE (two separate cells). (f) Quantitative analysis of the mean frequency (\% of control) of spontaneous currents in hippocampal cells in control $(=100 \%)$ and after addition of 5-HT $(n=4)$ and NE $(n=5)$. Note that both drugs significantly increased the spontaneous current frequency relative to control: $* p<0.05$; $* * x<0.0$ I; and ${ }^{*} * * p<0.00$ I.

neurons and a selective increase in the apical dendrites of CA3 neurons. We show here for the first time, that the exon 6 BDNF splice variant largely accounts for the dendritic localization of BDNF mRNA in CA3 in vivo in response to antidepressant treatments, which can be reproduced in vitro by activation of 5-HTor NE receptors.

Our results add one further piece of evidence to the neurotrophin hypothesis of antidepressant action in the hippocampus, which indicates the DG-CA3 axis as a major biological substrate for an effective action of antidepressant treatments (Castren, 2004; Duman and Monteggia, 2006). According to this model, both physical exercise and antidepressants stimulate BDNF production and secretion from DG granule cells to provide local trophic support for neuronal precursor survival (Santarelli et al, 2003) (Figure 7; 1.BDNF), and differentiation including formation of both basal dendrites and axonal branchings (Figure 7, 2.BDNF. Danzer et al, 2002). Following differentiation, newborn DG granule cells send out new axons that navigate towards the CA3 (Castren, 2004) (Figure 7, blue axons). Previous studies on TrkB knockout mice have found that connectivity to the target, but not axon navigation, is affected in these mutants, suggesting that BDNF is essential to promote synaptogenesis (Cohen-Cory et al, 2010; Jeanneteau et al, 2010; Martinez et al, 1998). Our study shows that physical exercise and two different antidepressants can induce BDNF 


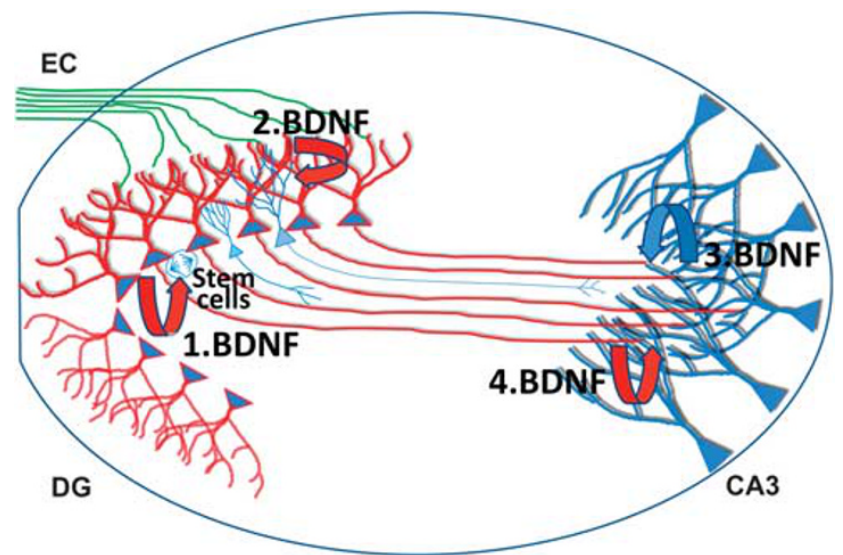

Figure 7 Revised model of the neurotrophic effects of antidepressant drugs. Brain-derived neurotrophic factor (BDNF) released from dentate gyrus (DG) granule cells is shown in red, while BDNF released from CA3 neurons is shown in blue. (I.BDNF) Exercise and antidepressants stimulate production and secretion of BDNF from DG granule cells providing local trophic support for survival and differentiation of DG subgranular neural stem cells and (2.BDNF) dendrites. (3.BDNF) Local production and release of BDNF from apical dendrites of CA3 neurons may provide the targetderived trophic support to promote innervation of CA3 from newly formed mossy fibers. (4.BDNF) At the same time, anterogradely transported BDNF in mossy fibers supports the further dendritic targeting of BDNF mRNA in CA3 neurons.

production in apical dendrites of CA3 neurons, suggesting that CA3 neurons may provide the target-derived trophic support to promote synaptic connections with mossy fibers (Figure 7; 3.BDNF). The ability of hippocampal neurons to release BDNF from dendrites is well demonstrated (Kuczewski et al, 2009). At the same time, BDNF anterogradely transported in mossy fibers (Smith et al, 1997) (Figure 7; 4.BDNF) may support dendritic targeting of BDNF mRNA in CA3 neurons through a well-known mechanism involving PI3K signaling (Righi et al, 2000).

The local increase of BDNF production in CA3 dendrites induced by antidepressants may have a dual functional significance, to promote and support synaptic contacts of mossy fibers to CA3 dendrites and to support dendritic arborization of CA3 neurons. Similarly, exercise can increase production of both BDNF and synapsin I in CA3 and DG, respectively, and promote an increase in dendritic length and spine density in CA3 pyramidal neurons (Vaynman et al, 2004; Yau et al, 2011). Evidence from studies on stress-induced hippocampal network remodeling also supports this view. Consistently replicated studies have shown that chronic stress produces a simplification of dendritic arbor in CA3 hippocampal neurons that is not observed in CA1 and can be specifically reversed by antidepressant treatments through an increase in BDNF (Conrad, 2006; Wood et al, 2004). Of note, heterozygous $\mathrm{BDNF} \pm$ transgenic mice or rats with CA3-localized BDNF knockdown present shorter and simplified CA3 apical dendritic arbors, like those observed in stressed wild-type mice (Magarinos et al, 2011; Taliaz et al, 2010). Furthermore, also kindling specifically enhances BDNF mRNA targeting in CA3 dendrites (Tongiorgi et al, 2004) and induces a striking localization of phosphorylated TrkB receptor labeling in CA3 stratum lucidum (Binder et al, 1999). The parallelism with the kindling paradigm is interesting because antidepressants produce a rapid autophosphorylation of $\operatorname{TrkB}$, which is required for the antidepressant-induced behavioral effects (Saarelainen et al, 2003).

Our study provides new evidence in support of our previously proposed 'spatial code hypothesis', according to which a neuron is able to finely tune the local availability of BDNF owing to a selective segregation and translation of different BDNF transcripts in distinct subcellular districts (Chiaruttini et al, 2008; Tongiorgi, 2008). Several antidepressants and mood stabilizers were shown to have a modulatory effect on transcription of BDNF splice variants with a highly dynamic expression profile depending on the drug used and treatment duration (Dias et al, 2003; RussoNeustadt et al, 2004). For instance, the mood stabilizers lithium and valproate selectively activate promoter 6 of BDNF (Yasuda et al, 2009), while chronic duloxetine treatment induces enhanced mRNA levels for exons 1 and 4; however, the expression of exon 6 was reduced in the cortex (Calabrese et al, 2007). In our study, the treatments considered caused an increase in BDNF transcription and a specific translocation in CA3 distal dendrites of the exon 6 BDNF mRNA isoform, while in the case of exon 4, which was previously found in the soma and proximal dendrites (Aliaga et al, 2009; Baj et al, 2011), we found proximal or no dendritic staining and a decrease in CA3 following RBX treatment. Hence, these results are further evidence that enhanced BDNF mRNA translocation in distal dendrites is not a direct consequence of increased global transcription (Tongiorgi, 2008). The decreased expression of exon 4 observed following RBX treatment is in line with a previous study, which described a highly dynamic transcription profile for BDNF transcripts during antidepressant treatment, and showing that with RBX, the BDNF isoform 4, after an initial increase at days 2 and 7, returned to baseline at 14 days (Russo-Neustadt et al, 2004). Of note, in a previous study (Molteni et al, 2006), we also measured an increase in total BDNF mRNA in the CA3-stratum lucidum in animals treated with FLX, but did not reach the statistical significance owing to limited number of samples analyzed. These results can be reinterpreted in light of the spatial code hypothesis of BDNF transcript usage. Accordingly, upregulation of exon 6 with the release of BDNF from dendrites may be required for the formation of new DG-CA3 connections, while other transcripts, through release from the cell soma, may be involved in neuronal survival and in supporting synapses located on the soma and proximal dendrites. In agreement with this view, transgenic mice with selective deletion of $B D N F$ exon 4 showed specific deficits in GABAergic transmission (Sakata et al, 2009) and GABAergic synapses are known to be particularly concentrated on the soma and proximal dendrites of hippocampal neurons (Megias et al, 2001). Along this line, further investigations on the definition of which BDNF splice variants are required to obtain the effects of antidepressants are warranted. It is expected that the results of this study, together with the growing information on the transcriptional regulation of the numerous BDNF promoters (Pruunsild et al, 2011), will contribute to a more selective search for new antidepressant drugs or to a more rational use of the existing antidepressants acting through upregulation of specific BDNF transcripts. 


\section{ACKNOWLEDGEMENTS}

The present work has been supported by MIUR Prin Grant (to ET, MP). We thank Antonio Malgaroli and Laura Ballerini for critically reading the paper and Andy Constanti for his thorough revision. This study is dedicated to the memory of Prof Francesco Langone.

\section{DISCLOSURE}

The authors declare that over the past 3 years Maurizio Popoli has received compensation and/or research funding from Servier and Fidia Pharmaceuticals.

\section{REFERENCES}

Adachi M, Barrot M, Autry AE, Theobald D, Monteggia LM (2008). Selective loss of brain-derived neurotrophic factor in the dentate gyrus attenuates antidepressant efficacy. Biol Psychiatry 63: 642-649.

Aid T, Kazantseva A, Piirsoo M, Palm K, Timmusk T (2007). Mouse and rat BDNF gene structure and expression revisited. J Neurosci Res 85: 525-535.

Aliaga EE, Mendoza I, Tapia-Arancibia L (2009). Distinct subcellular localization of BDNF transcripts in cultured hypothalamic neurons and modification by neuronal activation. J Neural Transm 116: 23-32.

Baj G, Leone E, Chao MV, Tongiorgi E (2011). Spatial segregation of BDNF transcripts enables BDNF to differentially shape distinct dendritic compartments. Proc Natl Acad Sci USA 108: 16813-16818.

Binder DK, Routbort MJ, McNamara JO (1999). Immunohistochemical evidence of seizure-induced activation of trk receptors in the mossy fiber pathway of adult rat hippocampus. J Neurosci 19: 4616-4626.

Bjornebekk A, Mathe AA, Brene S (2005). The antidepressant effect of running is associated with increased hippocampal cell proliferation. Int J Neuropsychopharmacol 8: 357-368.

Calabrese F, Molteni R, Maj PF, Cattaneo A, Gennarelli M, Racagni $\mathrm{G}$ et al. (2007). Chronic duloxetine treatment induces specific changes in the expression of BDNF transcripts and in the subcellular localization of the neurotrophin protein. Neuropsychopharmacology 32: 2351-2359.

Capsoni S, Tongiorgi E, Cattaneo A, Domenici L (1999). Differential regulation of brain-derived neurotrophic factor messenger RNA cellular expression in the adult rat visual cortex. Neuroscience 93: 1033-1040.

Castren E (2004). Neurotrophic effects of antidepressant drugs. Curr Opin Pharmacol 4: 58-64.

Castren E, Rantamaki T (2010). The role of BDNF and its receptors in depression and antidepressant drug action: reactivation of developmental plasticity. Dev Neurobiol 70: 289-297.

Chiaruttini C, Sonego M, Baj G, Simonato M, Tongiorgi E (2008). BDNF mRNA splice variants display activity-dependent targeting to distinct hippocampal laminae. Mol Cell Neurosci 37: 11-19.

Cohen-Cory S, Kidane AH, Shirkey NJ, Marshak S (2010). Brainderived neurotrophic factor and the development of structural neuronal connectivity. Dev Neurobiol 70: 271-288.

Conrad CD (2006). What is the functional significance of chronic stress-induced CA3 dendritic retraction within the hippocampus? Behav Cogn Neurosci Rev 5: 41-60.

Cotman CW, Berchtold NC (2002). Exercise: a behavioral intervention to enhance brain health and plasticity. Trends Neurosci 25: 295-301.
Danzer SC, Crooks KR, Lo DC, McNamara JO (2002). Increased expression of brain-derived neurotrophic factor induces formation of basal dendrites and axonal branching in dentate granule cells in hippocampal explant cultures. J Neurosci 22: 9754-9763.

Dias BG, Banerjee SB, Duman RS, Vaidya VA (2003). Differential regulation of brain derived neurotrophic factor transcripts by antidepressant treatments in the adult rat brain. Neuropharmacology 45: 553-563.

Dow AL, Russell DS, Duman RS (2005). Regulation of activin mRNA and Smad2 phosphorylation by antidepressant treatment in the rat brain: effects in behavioral models. J Neurosci 25: 4908-4916.

Duman RS, Monteggia LM (2006). A neurotrophic model for stress-related mood disorders. Biol Psychiatry 59: 1116-1127.

Garzon DJ, Fahnestock M (2007). Oligomeric amyloid decreases basal levels of brain-derived neurotrophic factor (BDNF) mRNA via specific downregulation of BDNF transcripts IV and $\mathrm{V}$ in differentiated human neuroblastoma cells. J Neurosci 27: 2628-2635.

Hamill OP, Marty A, Neher E, Sakmann B, Sigworth FJ (1981). Improved patch-clamp techniques for high-resolution current recording from cells and cell-free membrane patches. Pflugers Arch 391: 85-100.

Hughes IE, Smith JA (1978). The stability of noradrenaline in physiological saline solutions. J Pharm Pharmacol 30: 124-126.

Ivy AS, Rodriguez FG, Garcia C, Chen MJ, Russo-Neustadt AA (2003). Noradrenergic and serotonergic blockade inhibits BDNF mRNA activation following exercise and antidepressant. Pharmacol Biochem Behav 75: 81-88.

Jeanneteau F, Deinhardt K, Miyoshi G, Bennett AM, Chao MV (2010). The MAP kinase phosphatase MKP-1 regulates BDNFinduced axon branching. Nat Neurosci 13: 1373-1379.

Kuczewski N, Porcher C, Lessmann V, Medina I, Gaiarsa JL (2009). Activity-dependent dendritic release of BDNF and biological consequences. Mol Neurobiol 39: 37-49.

Ma Q (2008). Beneficial effects of moderate voluntary physical exercise and its biological mechanisms on brain health. Neurosci Bull 24: 265-270.

Magarinos AM, Li CJ, Gal Toth J, Bath KG, Jing D, Lee FS et al. (2011). Effect of brain-derived neurotrophic factor haploinsufficiency on stress-induced remodeling of hippocampal neurons. Hippocampus 21: 253-264.

Martinez A, Alcantara S, Borrell V, Del Rio JA, Blasi J, Otal R et al. (1998). TrkB and TrkC signaling are required for maturation and synaptogenesis of hippocampal connections. J Neurosci 18: 7336-7350.

Megias M, Emri Z, Freund TF, Gulyas AI (2001). Total number and distribution of inhibitory and excitatory synapses on hippocampal CA1 pyramidal cells. Neuroscience 102: 527-540.

Molteni R, Calabrese F, Bedogni F, Tongiorgi E, Fumagalli F, Racagni $G$ et al. (2006). Chronic treatment with fluoxetine upregulates cellular BDNF mRNA expression in rat dopaminergic regions. Int J Neuropsychopharmacol 9: 307-317.

Palop JJ, Roberson ED, Cobos I (2011). Step-by-step in situ hybridization method for localizing gene expression changes in the brain. Methods Mol Biol 670: 207-230.

Pattabiraman PP, Tropea D, Chiaruttini C, Tongiorgi E, Cattaneo A, Domenici L (2005). Neuronal activity regulates the developmental expression and subcellular localization of cortical BDNF mRNA isoforms in vivo. Mol Cell Neurosci 28: 556-570.

Pruunsild P, Kazantseva A, Aid T, Palm K, Timmusk T (2007). Dissecting the human BDNF locus: bidirectional transcription, complex splicing, and multiple promoters. Genomics 90: 397-406.

Pruunsild P, Sepp M, Orav E, Koppel I, Timmusk T (2011). Identification of cis-elements and transcription factors regulating neuronal activity-dependent transcription of human BDNF gene. J Neurosci 31: 3295-3308. 
Righi M, Tongiorgi E, Cattaneo A (2000). Brain-derived neurotrophic factor (BDNF) induces dendritic targeting of BDNF and tyrosine kinase B mRNAs in hippocampal neurons through a phosphatidylinositol-3 kinase-dependent pathway. J Neurosci 20: 3165-3174.

Russo-Neustadt A, Beard RC, Cotman CW (1999). Exercise, antidepressant medications, and enhanced brain derived neurotrophic factor expression. Neuropsychopharmacology 21: 679-682.

Russo-Neustadt AA, Alejandre H, Garcia C, Ivy AS, Chen MJ (2004). Hippocampal brain-derived neurotrophic factor expression following treatment with reboxetine, citalopram, and physical exercise. Neuropsychopharmacology 29: 2189-2199.

Russo-Neustadt AA, Chen MJ (2005). Brain-derived neurotrophic factor and antidepressant activity. Curr Pharm Des 11: $1495-1510$.

Saarelainen T, Hendolin P, Lucas G, Koponen E, Sairanen M, MacDonald E et al. (2003). Activation of the TrkB neurotrophin receptor is induced by antidepressant drugs and is required for antidepressant-induced behavioral effects. J Neurosci 23: 349-357.

Sakata K, Woo NH, Martinowich K, Greene JS, Schloesser RJ, Shen L et al. (2009). Critical role of promoter IV-driven BDNF transcription in GABAergic transmission and synaptic plasticity in the prefrontal cortex. Proc Natl Acad Sci USA 106: 5942-5947.

Santarelli L, Saxe M, Gross C, Surget A, Battaglia F, Dulawa S et al. (2003). Requirement of hippocampal neurogenesis for the behavioral effects of antidepressants. Science 301: 805-809.

Smith MA, Zhang LX, Lyons WE, Mamounas LA (1997). Anterograde transport of endogenous brain-derived neurotrophic factor in hippocampal mossy fibers. Neuroreport 8: 1829-1834.

Steward O, Schuman EM (2001). Protein synthesis at synaptic sites on dendrites. Annu Rev Neurosci 24: 299-325.

Swanger SA, Bassell GJ, Gross C (2011). High-resolution fluorescence in situ hybridization to detect mRNAs in neuronal compartments in vitro and in vivo. Methods Mol Biol 714: 103-123.

Taliaz D, Stall N, Dar DE, Zangen A (2010). Knockdown of brainderived neurotrophic factor in specific brain sites precipitates behaviors associated with depression and reduces neurogenesis. Mol Psychiatry 15: 80-92.
Tanti A, Belzung C (2010). Open questions in current models of antidepressant action. Br J Pharmacol 159: 1187-1200.

Tardito D, Musazzi L, Tiraboschi E, Mallei A, Racagni G, Popoli M (2009). Early induction of CREB activation and CREB-regulating signalling by antidepressants. Int J Neuropsychopharmacol 12: $1367-1381$.

Tardito D, Perez J, Tiraboschi E, Musazzi L, Racagni G, Popoli M (2006). Signaling pathways regulating gene expression, neuroplasticity, and neurotrophic mechanisms in the action of antidepressants: a critical overview. Pharmacol Rev 58: 115-134.

Tongiorgi E (2008). Activity-dependent expression of brainderived neurotrophic factor in dendrites: facts and open questions. Neurosci Res 61: 335-346.

Tongiorgi E, Armellin M, Giulianini PG, Bregola G, Zucchini S, Paradiso B et al. (2004). Brain-derived neurotrophic factor mRNA and protein are targeted to discrete dendritic laminas by events that trigger epileptogenesis. J Neurosci 24: 6842-6852.

Tongiorgi E, Righi M, Cattaneo A (1997). Activity-dependent dendritic targeting of BDNF and TrkB mRNAs in hippocampal neurons. J Neurosci 17: 9492-9505.

Tongiorgi E, Righi M, Cattaneo A (1998). A non-radioactive in situ hybridization method that does not require RNAse-free conditions. J Neurosci Methods 85: 129-139.

Trivedi MH, Greer TL, Grannemann BD, Chambliss HO, Jordan AN (2006). Exercise as an augmentation strategy for treatment of major depression. J Psychiatr Pract 12: 205-213.

Vaynman S, Ying Z, Gomez-Pinilla F (2004). Exercise induces BDNF and synapsin I to specific hippocampal subfields. J Neurosci Res 76: 356-362.

Wood GE, Young LT, Reagan LP, Chen B, McEwen BS (2004). Stress-induced structural remodeling in hippocampus: prevention by lithium treatment. Proc Natl Acad Sci USA 101: 3973-3978.

Yasuda S, Liang MH, Marinova Z, Yahyavi A, Chuang DM (2009). The mood stabilizers lithium and valproate selectively activate the promoter IV of brain-derived neurotrophic factor in neurons. Mol Psychiatry 14: 51-59.

Yau SY, Lau BW, Tong JB, Wong R, Ching YP, Qiu G et al. (2011). Hippocampal neurogenesis and dendritic plasticity support running-improved spatial learning and depression-like behaviour in stressed rats. PLoS One 6: e24263.

Yoshii A, Constantine-Paton M (2010). Postsynaptic BDNF-TrkB signaling in synapse maturation, plasticity, and disease. Dev Neurobiol 70: 304-322.

Supplementary Information accompanies the paper on the Neuropsychopharmacology website (http://www.nature.com/npp) 